\title{
Chromatographic method for the simultaneous quantification of dapsone and clofazimine in nanoformulations
}

\author{
Sandia Machado $^{1 \dagger}$ Sara R. Fernandes ${ }^{1,2 \dagger}$ Luise L. Chaves $^{1}$ Sofia A. C. Lima \\ Eduarda M. P. Silva ${ }^{1}$ Luísa Barreiros ${ }^{1,2 *} \quad$ Salette Reis $^{1} \quad$ Marcela A. Segundo $^{1}$ \\ ${ }^{1}$ LAQV, REQUIMTE, Departamento de $\quad{ }^{2}$ Núcleo de Investigação e Intervenção em \\ Ciências Químicas, Faculdade de Farmácia, Farmácia (NIIF), Centro de Investigação em \\ Universidade do Porto, Porto, Portugal Saúde e Ambiente (CISA), Escola Superior de \\ Correspondence \\ Saúde, Instituto Politécnico do Porto, Porto, \\ Portugal \\ †These authors contributed equally to this \\ work. \\ Professor Marcela A. Segundo, LAQV,
} REQUIMTE, Departamento de Ciências Químicas, Faculdade de Farmácia, Universidade do Porto, Rua de Jorge Viterbo Ferreira 228, 4050-313 Porto, Portugal. Email: msegundo@ff.up.pt

*Additional corresponding author Dr. Luísa Barreiros

Email:1barreiros@ff.up.pt

Article Related Abbreviations:

CLZ, clofazimine;

DAP, dapsone;

DLS, dynamic light scattering;

PDI, polydispersity index;

PLGA, poly(lactic-co-glycolic acid);

PVA, polyvinyl alcohol;

$\mathrm{RT}$, room temperature

\section{INTRODUCTION}

Leprosy is a chronic infectious disease caused by Mycobacterium leprae, an intracellular bacillus transmitted from an infected person to others through body fluids, representing a public health threat in several countries, namely, in India, Brazil, and Indonesia [1]. The current treatment of this disease is based on a multidrug therapy that includes combinations of dapsone (DAP), clofazimine (CLZ), and rifampicin
The low bioavailability and nonspecific distribution of dapsone and clofazimine, commonly applied in combination for the treatment of leprosy, can produce toxic effects. Nanotechnological approaches enhance the delivery of these drugs. Therefore, a high-performance liquid chromatography method was developed for the simultaneous determination of dapsone and clofazimine loaded in nanoformulations for quality control purposes. Chromatographic separation was achieved on a reversedphase Kinetex core-shell C18 column, followed by spectrophotometric detection at $280 \mathrm{~nm}$. Considering the different physicochemical properties of dapsone and clofazimine, elution was performed in gradient mode using an aqueous acetate buffer $(50 \mathrm{mmol} / \mathrm{L}, \mathrm{pH} 4.8)$ and an increasing acetonitrile content from 27 to $63 \% \mathrm{v} / \mathrm{v}$ at a flow rate of $1.0 \mathrm{~mL} / \mathrm{min}$ with retention times of 6.2 and $14.0 \mathrm{~min}$, respectively. The method was validated according to the European Medicines Agency guideline and it was found to be specific, accurate (99.6-114.0\%), and precise for intra- (RSD $\leq 1.8 \%$ ) and interday assays (RSD $\leq 12.5 \%$ ). Both drugs showed stability after $24 \mathrm{~h}$ at room temperature and over three freeze-thaw cycles with recoveries $\geq 86.2 \%$. Low temperature $\left(4^{\circ} \mathrm{C}\right)$ in the autosampler caused the precipitation of clofazimine and must be avoided. The validated method was successfully applied in the quantification of both drugs in nanoformulations.

\section{K E Y W O R D S}

bioavailability, core-shell columns, leprosy, nanoparticles to treat multibacillary leprosy, and combination of DAP with rifampicin for treatment of paucibacillary leprosy [2,3]. Although the multidrug therapy shows a good efficacy in the treatment of leprosy, many patients develop potentially harmful side effects that may occur during or after treatment with these drugs [4].

DAP (4-[(4-aminobenzene)sulfonyl]aniline) is an aniline derivative included in the group of synthetic sulfones. Solubility of DAP varies over a wide range depending on the solvent used, but in general, this compound shows low solubility, found to result in a low therapeutic index and high microbial resistance. The mechanism of action is characterized by dual function, with antimicrobial and anti-inflammatory properties [5]. CLZ (N,5-bis(4-chlorophenyl)-3-(propano- 
2-ylimino)-3,5-dihydrophenazin-2-amine), a lipophilic rhimophenazine dye, also possesses antimicrobial and antiinflammatory activities [6].

The use of nanotechnological tools to enhance the delivery of these drugs has been proposed to improve their efficacy, bioavailability, and to reduce unwanted toxic effects [713]. In this context, several methods have been reported for the determination of DAP and CLZ in different samples, including pharmaceutical formulations [14], human and rat plasma [15,16], human blood [17], and tissues [18]. Besides direct UV methods [19,20], HPLC methods in combination with UV or MS are most frequently used for the determination of these compounds. MS detection is a sensitive technique but it requires special equipments and highly skilled operators. Moreover, the expected drug levels in nanoformulations can be reached by UV detection, despite its lower sensitivity [21].

The determination of drug loading in nanodelivery systems is still an active topic of research, comprising approaches that provide the total amount of drug [22-25] or that can distinguish between the free and the entrapped drug [26-28]. The last approach is highly time-consuming, as additional separation process (SPE, ultrafiltration) must be applied, making it more suitable for pharmacokinetic/pharmacodynamic studies where the effective concentration of free drug must be known. For quality control purposes or assessment of entrapment efficiency, the determination of total loaded drug is sufficient, provided that the preparation media containing free drug is removed and that disruption of nanoparticles is established. This last approach is also advantageous when compared to the evaluation of drug loading based on measurement of the drug remaining on the supernatant during nanoparticles preparation.

To the best of our knowledge, there is no chromatographic method that allows the simultaneous determination of DAP and CLZ, either free or loaded in nanoparticles. Therefore, the aim of this work was the development and validation of an HPLC-UV method for the quantification of both compounds in a single run for estimation of entrapment efficiency during the development of nanoformulations of DAP and CLZ.

\section{2 | MATERIALS AND METHODS}

\section{1 | Chemicals and solutions}

DAP (4-[(4-aminobenzene)sulfonyl]aniline), CLZ (N,5-bis (4-chlorophenyl)-3-(propano-2-ylimino)-3,5-dihydrophenazin-2-amine), polyvinyl alcohol (PVA), Tween ${ }^{\circledR} 80$, and sodium acetate were purchased from Sigma-Aldrich ( $\mathrm{St}$ Louis, MO, USA). ACN (LiChrosolv HPLC grade), methanol (LiChrosolv HPLC grade), and acetic acid were obtained from VWR Chemicals (Radnor, PA, USA). Water from arium water purification system (resistivity $>18 \mathrm{M} \Omega \mathrm{cm}$,
Sartorius, Goettingen, Germany) was used for the preparation of solutions. Poly(lactic-co-glycolic acid) (PLGA) (50:50 Purasorb® PDLG 5002A) was a kind gift from Purac Biomaterials (Gorinchem, The Netherlands). Polyvinylpyrrolidone K30 was obtained from Fluka (Buchs, Switzerland).

Acetic acid/acetate buffer $(50 \mathrm{mM}, \mathrm{pH} 4.8)$ was prepared by dissolving $10.20 \mathrm{~g}$ of sodium acetate in ca. $100 \mathrm{~mL}$ of water, followed by addition of $2.86 \mathrm{~mL}$ of acetic acid, and water up to $250 \mathrm{~mL}$. The buffer solution was then filtered using $0.22 \mu \mathrm{m}$ Millipore GVWP filter and degassed in an ultrasonic bath for 30 min prior to use. Other components of the mobile phase were degassed likewise.

Stock standard solutions of DAP and CLZ were prepared in $\mathrm{ACN}$ at 1.0 and $0.5 \mathrm{~g} / \mathrm{L}$, respectively. All stock standard solutions were stored at $4^{\circ} \mathrm{C}$ protected from light and used within seven days. The intermediate solution containing $100 \mathrm{mg} / \mathrm{L}$ of each analyte was prepared daily in ACN/water/acetate buffer $(\mathrm{pH} 4.8 ; 50 \mathrm{mM})(40: 50: 10 \mathrm{v} / \mathrm{v})$. Working standards were prepared from the intermediate solution, ranging from 0.5 to $5.0 \mathrm{mg} / \mathrm{L}$, using the same solvent.

\section{2 | Chromatographic analysis}

Chromatographic analysis was performed on Jasco HPLC system (Easton, PA, USA) equipped with a PU-2089 pump, an AS-2057 autosampler, a LC-Net II/ADC controller, and a Jasco MD-2015 photo diode array detector. Standards and samples were injected $(20 \mu \mathrm{L})$ into a reversed-phase Kinetex core-shell C18 column $(250 \times 4.6 \mathrm{~mm} ; 5 \mu \mathrm{m}$ particle size; $100 \AA$ ).

The system was run in gradient mode using a mobile phase consisting of three components: (A) ACN/water (30:70), (B) ACN/water (90:10), and (C) acetic acid/acetate buffer ( $\mathrm{pH} 4.8,50 \mathrm{mM})$. Hence, gradient elution mode was performed by increasing ACN content from 27 to $63 \% \mathrm{v} / \mathrm{v}$, and maintaining a constant concentration of acetic acid/acetate buffer ( $\mathrm{pH} 4.8,50 \mathrm{mM}$ ) with a total flow rate of $1.0 \mathrm{~mL} / \mathrm{min}$. Initial experiments using $\mathrm{ACN}<27 \% \mathrm{v} / \mathrm{v}$ required an extra solvent line (D) containing deionized water. Determinations were performed at room temperature (RT) $\left(20 \pm 2^{\circ} \mathrm{C}\right)$ and the detection wavelength was $280 \mathrm{~nm}$.

\section{3 | Method validation}

The chromatographic method was validated for specificity, linearity, working range, accuracy, intra- and interday precision, LOD, LOQ, and stability in accordance with European Medicines Agency and International Conference on Harmonisation of Technical Requirements for Registration of Pharmaceuticals for Human Use guidelines [29,30].

Specificity was determined by analyzing six blanks of nanoformulations. To evaluate linearity, calibration curves were prepared and analyzed in triplicate, comprising three 
independent experiments. Data were fitted to least squares linear regression concerning peak area versus concentration for six standards prepared in mobile phase $(0.5,1,2,3,4$, and $5 \mathrm{mg} / \mathrm{L}$ ) and by analysis of the respective response factors (i.e., peak area divided by concentration of each standard sample). Back-calculated concentrations were also obtained.

The accuracy and precision of the assay were assessed by analyzing quality control (QC) samples at three concentrations levels $(0.5,2$, and $5 \mathrm{mg} / \mathrm{L})$. Accuracy (\%) was determined from the percentage ratio of the measured nominal concentration ((mean of measured concentration) / (nominal concentration) $\times 100 \%)$. Precision was evaluated by the coefficient of variation ((standard deviation/mean of measured concentration) $\times 100 \%)$.

Intraday (within-run) values were obtained by replicate analyses $(n=6)$ followed by interpolation in calibration curves prepared on the same day. Interday (between-run) values were obtained from three independent experiments.

LOD and LOQ values for DAP and CLZ in each matrix ( $n=10$ ) were determined by the $\mathrm{S} / \mathrm{N}$ ratio, defined as the concentrations that originated $\mathrm{S} / \mathrm{N}=3: 1$ and $10: 1$, respectively.

The short-term stability was assessed by maintaining the QC samples at RT for $24 \mathrm{~h}$. Freeze-thaw stability of the samples was obtained over three freeze-thaw cycles, by thawing at RT for $2 \mathrm{~h}$ and refreezing for $24 \mathrm{~h}$. Autosampler stability of DAP/CLZ was tested by analysis of QC samples, which were stored in the autosampler tray of the HPLC instrument for $24 \mathrm{~h}$ at $4{ }^{\circ} \mathrm{C}$. The concentration of DAP and CLZ after each storage period was compared to the nominal concentration determined for the fresh samples, processed immediately after preparation.

\section{4 | Preparation, characterization of nanoformulations, and application to biological system}

DAP polymeric dispersions were prepared by the freezedrying method described previously [8]. At first, $200 \mathrm{mg}$ of DAP and $1000 \mathrm{mg}$ of Polyvinylpyrrolidone K30 were dissolved in ACN and water, respectively. After $48 \mathrm{~h}$ under magnetic stirring (RT 15 Power IKAMAG, Staufen, Germany), the solutions were then frozen at $-84^{\circ} \mathrm{C}$ for $24 \mathrm{~h}$. The samples were freeze-dried (Lyoquest ECO, Telstar) using a condenser temperature of $-65^{\circ} \mathrm{C}$ and pressure of $0.5 \mathrm{mbar}$, during $48 \mathrm{~h}$, in order to obtain a dry cake. The samples were stored in desiccator for a complete drying.

CLZ was loaded in polymeric nanoparticles of PLGA using the single emulsion-solvent evaporation technique [7]. Briefly, $40 \mathrm{mg}$ of PLGA and $4 \mathrm{mg}$ of CLZ were dissolved in acetone, and then poured slowly to $10 \mathrm{~mL}$ of an aqueous solution of PVA $1 \% \mathrm{w} / \mathrm{v}$, under probe sonication with $70 \%$ amplitude. After $2 \mathrm{~min}$, the volume was set up to $20 \mathrm{~mL}$ with the PVA solution $(0.1 \% \mathrm{w} / \mathrm{v})$. The final emulsion was maintained under magnetic stirring (RT 15 Power IKAMAG) at $350 \mathrm{rpm}$ and RT until solvent evaporation. The obtained nanoparticles were washed three times with double deionized water, by centrifugation at $11200 \times g$ for $30 \mathrm{~min}$, using an Allegra X-15R centrifuge (Beckman Coulter, Brea, CA, USA).

The nanoformulations were characterized in terms of particle size and polydispersity index (PDI) through dynamic light scattering (DLS) using a ZetaPALS, Zeta Potential Analyzer (Brookhaven Instrument Corps, Holtsville, NY, USA), at $25^{\circ} \mathrm{C}$ with a light incidence angle of $90^{\circ}$. The nanoformulations were diluted with double deionized water until reaching a suitable concentration for the DLS measurement (count rate around 500). The nanoformulations were analyzed by HPLC within one week of preparation.

For permeability studies in biological systems, intestinal Caco-2 cells were selected, cultivated until forming a monolayer and incubated with a combination of nanoparticles containing DAP and CLZ (80 and $40 \mu \mathrm{g}$, respectively) in the apical side of the cell monolayer, at $37^{\circ} \mathrm{C}$ and $5 \% \mathrm{v} / \mathrm{v} \mathrm{CO}_{2}$ [31]. The amount of DAP and CLZ that permeated the monolayers was calculated from the concentrations measured in the basolateral compartment and expressed as a percentage of the initial added amount in the apical compartment.

\section{3 | RESULTS AND DISCUSSION}

\section{1 | Selection of chromatographic conditions}

DAP (Figure 1) is classified as a class II drug according to the Biopharmaceutics Classification System, and has high permeability and low solubility in water $(\log D=1.27, \mathrm{pH}>4.4$, Supporting Information Figure S1), presenting neutral charge for $\mathrm{pH}$ values $>4$ (Supporting Information Figure S2). CLZ (Figure 1$)$ is a highly hydrophobic molecule $(\log D=4.8$ at $\mathrm{pH} 4.0$, and $\log D=7.3$ at $\mathrm{pH}>7.6$, Supporting Information Figure S3). For $\mathrm{pH}$ values between 2.3 and 6.6, the positively charged species is predominant, with ionization occurring by protonation of the imine group and/or of the nitrogen atom of the dihydrophenazine heterocycle (Supporting Information Figure S4). For $\mathrm{pH}$ values above 6.6, the neutral form prevails, accounting for the significant decrease CLZ solubility

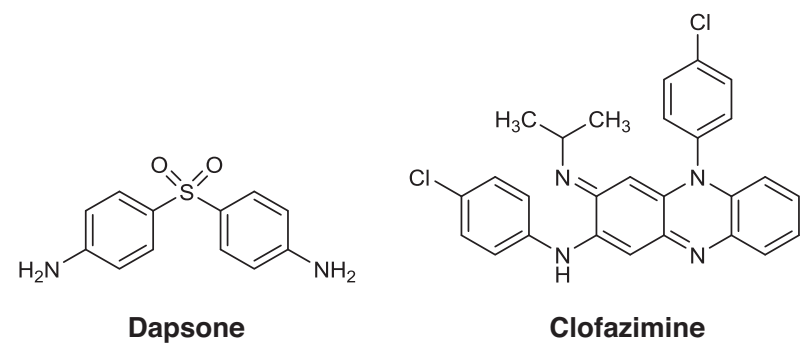

F I G U R E 1 Chemical structures of DAP and CLZ 
in aqueous phases. Hence, isocratic elution was not possible because the two analytes have substantially different physicochemical features at $\mathrm{pH}$ values compatible with operation in derivatized C18-silica columns. Therefore, the gradient elution was tested, using ACN as organic modifier and keeping a constant $\mathrm{pH}$ (4.8) by addition of acetic acid/acetate buffer at a constant fixed amount $(10 \% \mathrm{v} / \mathrm{v})$.

Initially, the organic modifier amount in the beginning of the chromatographic run was tested from 20 to $40 \% \mathrm{v} / \mathrm{v}$. ACN content was increased up to $80 \% \mathrm{v} / \mathrm{v}$ by the end of the gradient, implemented during $30 \mathrm{~min}$, starting from $3 \mathrm{~min}$ after sample injection. DAP was eluted within the gradient for initial ACN content of 21 and $27 \% \mathrm{v} / \mathrm{v}$ at 8.5 and $5.7 \mathrm{~min}$, respectively. Elution at $3.7 \mathrm{~min}$ was observed for an initial ACN content at $39 \% \mathrm{v} / \mathrm{v}$, close to the baseline disturbance associated to the column void volume (corresponding to ca. $2.5 \mathrm{~min}$ ). Therefore, initial content of $\mathrm{ACN}$ was fixed at $27 \% \mathrm{v} / \mathrm{v}$ to minimize the retention of DAP but still separating it from nonretained compounds present in the sample that will leave the column at void volume.

Concerning CLZ, elution took place within the gradient at 26.1, 24.4, and $19.4 \mathrm{~min}$ for an initial ACN content of 21, 27, and $39 \% \mathrm{v} / \mathrm{v}$, respectively. Considering that the gradient was implemented during $30 \mathrm{~min}$ and it started from $3 \mathrm{~min}$ after sample injection, the estimated percentage of ACN content required for CLZ elution (based on retention time) was $62 \%$ $\mathrm{v} / \mathrm{v}$. Therefore, further experiments were performed to establish the ACN content at the end of the gradient, using ACN at 54, 60, 63, 66, and $72 \% \mathrm{v} / \mathrm{v}$. Elution within the gradient was observed for ACN content above $63 \% \mathrm{v} / \mathrm{v}$, with retention time $<33 \mathrm{~min}$. For 54 and $60 \% \mathrm{v} / \mathrm{v}$, retention time of 38.2 and 34.3 min was observed, with a $10 \%$ decrease in the area attained for ACN at $54 \% \mathrm{v} / \mathrm{v}$, probably due to incomplete elution of CLZ from the column. Hence, for further experiments, $\mathrm{ACN}$ content at $60 \% \mathrm{v} / \mathrm{v}$ was chosen as target organic modifier composition at the end of gradient.

Subsequently, the time required for gradient implementation was evaluated between 3 and $30 \mathrm{~min}$, starting from $3 \mathrm{~min}$ after sample injection. The retention time for CLZ decreased from 34.6 to $15 \mathrm{~min}$ when the gradient was narrowed from 30 to 3 min. However, DAP peak was affected by baseline disturbance upon the sudden change in mobile phase composition. To circumvent this problem, the gradient beginning was delayed to $7 \mathrm{~min}$ after sample injection. The retention time for CLZ was then decreased from 38.3 to 17.6 min when the gradient was narrowed from 30 to $1 \mathrm{~min}$, without jeopardizing the DAP analysis. A further decrease of gradient beginning time to 5 min reduced even more the retention time of CLZ to $15.5 \mathrm{~min}$. Further experiments were performed with a higher ACN content at the end of the gradient $(63 \% \mathrm{v} / \mathrm{v})$, providing a retention time of CLZ of $14 \mathrm{~min}$. Using these conditions, DAP retention time was $6.2 \mathrm{~min}$. Column equilibration to initial run condition was achieved by reducing ACN content to $27 \% \mathrm{v} / \mathrm{v}$

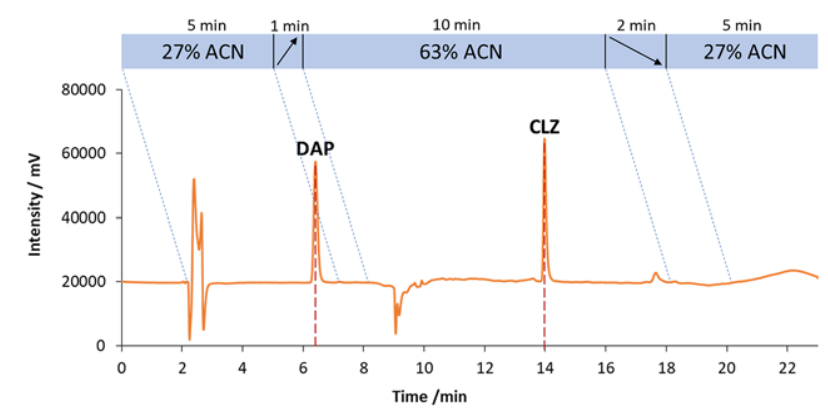

F I G U R E 2 Chromatograms of DAP and CLZ ( $2 \mathrm{mg} / \mathrm{L})$. The organic modifier (ACN) content during gradient elution is indicated in the bar above the graph. Dotted lines indicate gradient correspondence to the run time minus the time corresponding to the void volume

in $2 \mathrm{~min}$ and by keeping this composition during $5 \mathrm{~min}$, providing a total run time of $23 \mathrm{~min}$ (Figure 2).

Different injection volumes $(10,20$, and $50 \mu \mathrm{L})$ were also tested using standards containing 1 and $5 \mathrm{mg} / \mathrm{L}$. Calibration curves were established as absorbance versus injected mass. For both compounds, mass back-calculation provided values corresponding to $93.7-119 \%$ of injected mass, except for the injection volume of $10 \mu \mathrm{L}$ using $1 \mathrm{mg} / \mathrm{L}$ of CLZ, for which an overestimation was observed. Therefore, the injection volume of $20 \mu \mathrm{L}$ was chosen for further work. Nevertheless, the calibration range can be moved for higher concentrations (injection volume of $10 \mu \mathrm{L}$, standards above $1 \mathrm{mg} / \mathrm{L}$ ) or to lower concentrations (injection volume of $50 \mu \mathrm{L}$ ), with acceptable mass recoveries.

\section{2 | Method validation}

The validation of the analytical HPLC method was carried out by evaluating its selectivity, linearity, intra- and interday precision and accuracy, and stability.

For selectivity, analyses of blank samples of unloaded nanoformulations were performed as shown in Supporting Information Figure S5, where a chromatogram for DAP+CLZ standard is also presented. No interference from compounds present in the nanoformulations was observed as no peaks were seen at the retention times of target compounds (Supporting Information Figure S5).

The calibration curves for DAP and CLZ were linear and reproducible over the concentrations range, with correlation coefficients $>0.9979$. Typical calibration curves were $y=(55.0 \pm 0.8) \times 10^{3} x-1561 \pm 2344$ for DAP, and $y=$ $(70.6 \pm 0.9) \times 10^{3} x-2039 \pm 3004$ for CLZ. The backcalculated concentrations presented deviations $<15 \%$ from the nominal value, meeting the requirements of European Medicines Agency guideline. The calculated values of LOD and LOQ were 7 and $17 \mu \mathrm{g} / \mathrm{L}$ for DAP, 31 and $65 \mu \mathrm{g} / \mathrm{L}$ for CLZ. 
TA B L E 1 Accuracy and precision for the analysis of DAP and CLZ

\begin{tabular}{|c|c|c|c|c|c|c|c|}
\hline \multirow[b]{3}{*}{ Compound } & \multirow{3}{*}{$\begin{array}{l}\text { Nominal concentration } \\
(\mathrm{mg} / \mathrm{L})\end{array}$} & \multicolumn{3}{|l|}{ Intraday } & \multicolumn{3}{|l|}{ Interday } \\
\hline & & \multicolumn{3}{|c|}{ Measured concentration $(\mathrm{mg} / \mathrm{L})$} & \multicolumn{3}{|c|}{ Measured concentration $(\mathrm{mg} / \mathrm{L})$} \\
\hline & & Mean (mg/L) & Accuracy (\%) & $\overline{C V}(\%)$ & Mean (mg/L) & Accuracy (\%) & $\mathrm{CV}(\%)$ \\
\hline \multirow{2}{*}{ DAP } & 2 & 2.01 & 100.5 & 0.5 & 2.07 & 103.5 & 2.4 \\
\hline & 5 & 5.22 & 104.4 & 1 & 5.24 & 104.8 & 1.3 \\
\hline \multirow{2}{*}{ CLZ } & 2 & 2.04 & 102 & 1 & 1.98 & 99 & 4.5 \\
\hline & 5 & 4.98 & 99.6 & 0.8 & 4.79 & 95.8 & 10 \\
\hline
\end{tabular}

The intraday precision and accuracy were calculated by analyzing the QC samples at low, middle, and high values $(0.5,2.0$, and $5.0 \mathrm{mg} / \mathrm{L}$, Table 1$)$. The intraday precision for DAP and CLZ was $\leq 1.8 \%$, and accuracy ranged between 100.5 and $110.0 \%$ for DAP, and between 99.6 and $114.0 \%$ for CLZ. The interday precision for DAP and CLZ was $\leq 12.5 \%$, and accuracy ranged between 103.5 and $112.0 \%$ for DAP, and between 95.8 and $106.0 \%$ for CLZ. Both intra- and interday precision, as well as accuracy presented acceptable values for the two compounds, because precision for each concentration levels, represented as CV, did not exceed $15 \%$, and the accuracy range was between 95.8 and $114.0 \%$.

The stability of DAP and CLZ at laboratory temperature and in the autosampler was assessed by analyzing fresh samples and reanalyzing them after being kept during $24 \mathrm{~h}$ at RT $\left(20 \pm 2^{\circ} \mathrm{C}\right)$. DAP and CLZ showed stability after this period as depicted in Table 2, with recoveries ranging from 86.2 to $114.0 \%$. However, when stored in the autosampler during $24 \mathrm{~h}$ at $4^{\circ} \mathrm{C}$, precipitation was visible. CLZ deposition was confirmed when standards containing only this compound were tested. Therefore, samples must be placed in the autosampler at RT. The freeze-thaw stability of DAP and CLZ over three freeze-thaw cycles was also assessed, providing recovery values of 95.4-108.0\% (Table 2), showing the stability during sample storage and handling. Moreover, a suitable recovery was attained when RT was achieved, even after cold storage.

\section{3 | Application to evaluation of nanoformulations}

DLS analysis of the nanoformulations revealed particle size of $225 \pm 2 \mathrm{~nm}$ for amorphous polymeric dispersion nanoparticles carrying DAP, and $211 \pm 3 \mathrm{~nm}$ for PLGA polymeric nanoparticles carrying CLZ. The obtained nanoparticles exhibited polydispersity index values of 0.187 and 0.129 , respectively. Both values are $<0.2$, which are consistent with homogenous populations [32].

Most of the times, assessment of drug entrapment in nanoparticles is based on non-separative methods, including direct UV spectrophotometry of drug present in the supernatant of nanoparticles' preparation media. This assumes that drug not present in the supernatant is entrapped, which can lead to significant errors in quantification. Other issue to be tackled is the release of drug from nanoparticles matrix prior to quantification. For this, the nanoformulations were

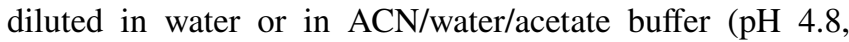
$50 \mathrm{mM})(40: 50: 10 \mathrm{v} / \mathrm{v} / \mathrm{v})$, following analysis by DLS. In water, DAP nanoformulations exhibited a population with an average size around $200 \mathrm{~nm}$. Using ACN/water/acetate buffer $(\mathrm{pH} 4.8,50 \mathrm{mM})(40: 50: 10 \mathrm{v} / \mathrm{v} / \mathrm{v})$ as solvent, no population was detected. Similarly, for CLZ nanoformulations, the formulation dispersed in water had a population with an average size of $230 \mathrm{~nm}$. In ACN/water/acetate buffer $(\mathrm{pH}$ $4.8,50 \mathrm{mM})(40: 50: 10 \mathrm{v} / \mathrm{v} / \mathrm{v})$ the population disappeared.

T A B L E 2 Stability of DAP and CLZ at different experimental conditions

\begin{tabular}{|c|c|c|c|c|c|c|c|}
\hline \multirow[b]{3}{*}{ Compound } & \multirow{3}{*}{$\begin{array}{l}\text { Nominal concentration } \\
(\mathrm{mg} / \mathrm{L})\end{array}$} & \multicolumn{3}{|c|}{ After $24 \mathrm{~h}$ at $\mathrm{RT}$} & \multicolumn{3}{|c|}{ After 3 freeze-thaw cycles } \\
\hline & & \multicolumn{3}{|c|}{ Measured concentration (mg/L) } & \multicolumn{3}{|c|}{ Measured concentration $(\mathrm{mg} / \mathrm{L})$} \\
\hline & & $\overline{M e a n}(\mathrm{mg} / \mathrm{L})$ & Accuracy (\%) & $\overline{\mathrm{CV}(\%)}$ & $\overline{\text { Mean }(\mathrm{mg} / \mathrm{L})}$ & Accuracy (\%) & $\mathrm{CV}(\%)$ \\
\hline \multirow{2}{*}{ DAP } & 2 & 1.91 & 95.5 & 1.6 & 2.06 & 103 & 1 \\
\hline & 5 & 5.07 & 101.4 & 0.6 & 4.93 & 98.6 & 0.4 \\
\hline CLZ & 5 & 4.31 & 86.2 & 0.7 & 4.77 & 95.4 & 0.8 \\
\hline
\end{tabular}


Additionally, count rates were $450-480$ for nanoparticles in water and they decreased to background values for nanoparticles in ACN/water/acetate buffer (pH 4.8, $50 \mathrm{mM}$ ) (40:50:10 $\mathrm{v} / \mathrm{v} / \mathrm{v})$. Therefore, a disruption of nanoparticle structure was observed for both formulations with consequent drug release.

Entrapment efficiency was evaluated as $54.8 \pm 0.1 \%$ for DAP and $24.9 \pm 0.2 \%$ for CLZ. Compared to previously reported efficiency entrapment values for other formulations, similar values were obtained for DAP loaded in surfacefunctionalized solid lipid nanoparticles based on cetyl palmitate [12], but lower than those reported for theospheres [9]. Concerning CLZ, better entrapment efficiency was reported for more hydrophobic formulations, based on hypromellose acetate succinate, lecithin, and zein [13]. This is expected, considering the hydrophobic character of CLZ.

Concerning permeability studies using Caco- 2 cell as a model of intestinal epithelium [31], the tested formulation containing both nanoparticles provided values of $\%$ permeated amount of $31.3 \pm 2.9 \%$ for DAP and $10.8 \pm 0.8 \%$ for CLZ (after $2 \mathrm{~h}$ ), and $52.5 \pm 9.1 \%$ for DAP and $39.4 \pm 3.1 \%$ for CLZ (after $8 \mathrm{~h}$ ), showing the sustained permeation of both formulations.

\section{4 | CONCLUDING REMARKS}

An HPLC method coupled with UV detection was developed and fully validated for quantification of DAP and CLZ in nanoformulations containing polymers. Separation was achieved using a core-shell $\mathrm{C} 18$ stationary phase and a mobile phase buffered at $\mathrm{pH} 4.8$, with gradient elution that permitted an efficient separation of the target compounds in a single run. Addition of $\mathrm{ACN}$ at $40 \% \mathrm{v} / \mathrm{v}$ allowed the disintegration of nanoparticle structures for further quantification of active compounds.

The developed HPLC-UV method proved to be sensitive, selective, accurate, and precise for the quantitative analysis of DAP and CLZ, in a concentration range suitable for application to nanoformulations. LOD and LOQ values in the $\mu \mathrm{g} / \mathrm{L}$ level were attained, being comparable or even lower than values previously reported in the literature. The proposed method was found to be suitable for the determination of drug entrapment efficiency in innovative nanoformulations.

\section{ACKNOWLEDGMENTS}

This work received financial support from the European Union (FEDER funds) and National Funds (FCT/MEC, Fundação para a Ciência e a Tecnologia and Ministério da Educação e Ciência) under the Partnership Agreement PT2020 UID/QUI/50006/2013-POCI/01/0145/FEDER/007265. E. M. P. Silva and S. A. C. Lima acknowledge funding from FEDER-Operational Competitiveness and Internationalization Programme (COMPETE 2020) through project NORTE01-0145-FEDER-000011. L. Barreiros thanks FCT and POPH (Programa Operacional Potencial Humano) for her Post-Doc grant (SFRH/BPD/89668/2012). L. L. Chaves thanks the CNPq Foundation, Ministry of Education of Brazil for the Doctoral fellowship 246514/2012-4. Technical assistance from Ms. Manuela Barros is acknowledged.

\section{REFERENCES}

1. World Health Organization, Global leprosy update, 2015: time for action, accountability and inclusion, 2016, 91, 405-420, http://www.who.int/lep/resources/who_wer9135/en/

2. Smith, C. S., Aerts, A., Saunderson, P., Kawuma, J., Kita, E., Virmond, M., Multidrug therapy for leprosy: a game changer on the path to elimination. Lancet Infect. Dis. 2017, 17, E293-E297.

3. Yamasaki, P. R., do Nascimento, D. C., Chelucci, R. C., Belone, A. D. F., Rosa, P. S., Diorio, S. M., de Melo, T. R. F., Barbieri, K. P., Placeres, M. C. P., Carlos, I. Z., Chung, M. C., dos Santos, J. L., Synthesis and evaluation of novel dapsone-thalidomide hybrids for the treatment of type 2 leprosy reactions. Bioorg. Med. Chem. Lett. 2014, 24, 3084-3087.

4. Anusuya, S., Natarajan, J., The eradication of leprosy: molecular modeling techniques for novel drug discovery. Expert. Opin. Drug Discov. 2013, 8, 1239-1251.

5. Wozel, G., Blasum, C., Dapsone in dermatology and beyond. Arch. Dermatol. Res. 2014, 306, 103-124.

6. Cholo, M. C., Steel, H. C., Fourie, P. B., Germishuizen, W. A., Anderson, R., Clofazimine: current status and future prospects. $J$. Antimicrob. Chemother. 2012, 67, 290-298.

7. Chaves, L. L., Lima, S. A. C., Vieira, A. C. C., Barreiros, L., Segundo, M. A., Ferreira, D., Sarmento, B., Reis, S., Development of PLGA nanoparticles loaded with clofazimine for oral delivery: assessment of formulation variables and intestinal permeability. Eur. J. Pharm. Sci. 2018, 112, 28-37.

8. Chaves, L. L., Vieira, A. C. C., Ferreira, D., Sarmento, B., Reis, S., Rational and precise development of amorphous polymeric systems with dapsone by response surface methodology. Int. J. Biol. Macromol. 2015, 81, 662-671.

9. dos Santos, G. S., Pereira, G. G., Bender, E. A., Colome, L. M., Guterres, S. S., de Carvalho, D. C. M., Weissmuller, G., Development and characterization of lipid nanoparticles for dapsone topical application. Quim. Nova 2012, 35, 1388-U1530.

10. Rojo, L., Fernandez-Gutierrez, M., Deb, S., Stevens, M. M., Roman, J. S., Designing dapsone polymer conjugates for controlled drug delivery. Acta Biomater. 2015, 27, 32-41. 
11. Valetti, S., Xia, X., Costa-Gouveia, J., Brodin, P., Bernet-Camard, M. F., Andersson, M., Feiler, A., Clofazimine encapsulation in nanoporous silica particles for the oral treatment of antibioticresistant Mycobacterium tuberculosis infections. Nanomedicine 2017, 12, 831-844.

12. Vieira, A. C. C., Chaves, L. L., Pinheiro, M., Ferreira, D., Sarmento, B., Reis, S., Design and statistical modeling of mannose-decorated dapsone-containing nanoparticles as a strategy of targeting intestinal M-cells. Int. J. Nanomed. 2016, 11, 2601-2617.

13. Zhang, Y. Y., Feng, J., McManus, S. A., Lu, H. D., Ristroph, K. D., Cho, E. J., Dobrijevic, E. L., Chan, H. K., Prud'homme, R. $\mathrm{K}$., Design and solidification of fast-releasing clofazimine nanoparticles for treatment of cryptosporidiosis. Mol. Pharm. 2017, 14, 3480-3488.

14. Salama, N., El Ries, M. A., Toubar, S., Hamide, M. A., Walash, M. I., Validated TLC and HPLC stability-indicating methods for the quantitative determination of dapsone. JPC-J. Planar Chromatogr.Mod. TLC 2012, 25, 65-71.

15. Kim, H. J., Seo, K. A., Kim, H. M., Jeong, E. S., Ghim, J. L., Lee, S. H., Lee, Y. M., Kim, D. H., Shin, J. G., Simple and accurate quantitative analysis of 20 anti-tuberculosis drugs in human plasma using liquid chromatography-electrospray ionization-tandem mass spectrometry. J. Pharm. Biomed. Anal. 2015, 102, 9-16.

16. Liu, Y., Li, X., Yang, C. J., Tai, S., Zhang, X. N., Liu, G. F., UPLCMS-MS method for simultaneous determination of caffeine, tolbutamide, metoprolol, and dapsone in rat plasma and its application to cytochrome P450 activity study in rats. J. Chromatogr. Sci. 2013, $51,26-32$

17. Mberu, E. K., Muhia, D. K., Minyiri, G. O., Njonge, E. W., Watkins, W. M., Measurement of physiological concentrations of dapsone and its monoacetyl metabolite: a miniaturised assay for liquid or filter paper-absorbed samples. J. Chromatogr. B-Biomed. Appl. 1996, 677, 385-387.

18. O'Connor, R., O'Sullivan, J. F., O'Kennedy, R., Determination of serum and tissue levels of phenazines including clofazimine. $J$. Chromatogr. B-Biomed. Appl. 1996, 681, 307-315.

19. Revanasiddappa, H. D., Manju, B., A spectrophotometric method for the determination of metoclopramide $\mathrm{HCl}$ and dapsone. $J$. Pharm. Biomed. Anal. 2001, 25, 631-637.

20. Li, H. Z., Ma, S. H., Zhang, H. M., Liu, J. M., Wu, Y. X., Cao, P. Q., Gao, X., Nano carrier mediated co-delivery of dapsone and clofazimine for improved therapeutic efficacy against tuberculosis in rats. Biomed. Res.-India 2017, 28, 1284-1289.

21. Kwadijk, S., Torano, J. S., High-performance liquid chromatographic method with ultraviolet detection for the determination of dapsone and its hydroxylated metabolite in human plasma. Biomed. Chromatogr. 2002, 16, 203-208.

22. Segundo, M. A., Abreu, V., Osorio, M. V., Nogueira, S., Lin, P. K. T., Cordeiro-da-Silva, A., Lima, S. A. C., Development and validation of HPLC method with fluorometric detection for quantification of bisnaphthalimidopropyldiaminooctane in animal tissues following administration in polymeric nanoparticles. J. Pharm. Biomed. Anal. 2016, 120, 290-296.
23. Cunha, R. R., Ribeiro, M., Munoz, R. A. A., Richter, E. M., Fast determination of codeine, orphenadrine, promethazine, scopolamine, tramadol, and paracetamol in pharmaceutical formulations by capillary electrophoresis. J. Sep. Sci. 2017, 40, 1815-1823.

24. Paul, P., Duchateau, T., Sanger-van de Griend, C., Adams, E., Van Schepdael, A., Capillary electrophoresis with capacitively coupled contactless conductivity detection method development and validation for the determination of azithromycin, clarithromycin, and clindamycin. J. Sep. Sci. 2017, 40, 3535-3544.

25. Zhang, Q., Yang, F. Q., Ge, L. Y., Hu, Y. J., Xia, Z. N., Recent applications of hydrophilic interaction liquid chromatography in pharmaceutical analysis. J. Sep. Sci. 2017, 40, 49-80.

26. Yamamoto, E., Hyodo, K., Ohnishi, N., Suzuki, T., Ishihara, H., Kikuchi, H., Asakawa, N., Direct, simultaneous measurement of liposome-encapsulated and released drugs in plasma by on-line SPE-SPE-HPLC. J. Chromatogr. B 2011, 879, 3620-3625.

27. Kimoto, A., Watanabe, A., Yamamoto, E., Higashi, T., Kate, M., Rapid analysis of DOXIL stability and drug release from DOXIL by HPLC using a glycidyl methacrylate-coated monolithic column. Chem. Pharm. Bull. 2017, 65, 945-949.

28. Xie, Y. P., Shao, N., Jin, Y., Zhang, L., Jiang, H., Xiong, N. J., $\mathrm{Su}, \mathrm{F} . \mathrm{M} ., \mathrm{Xu}, \mathrm{H}$. Y., Determination of non-liposomal and liposomal doxorubicin in plasma by LC-MS/MS coupled with an effective solid phase extraction: In comparison with ultrafiltration technique and application to a pharmacokinetic study. J. Chromatogr. B 2018, 1072, 149-160.

29. European Medicines Agency, Guideline on bioanalytical method validation EMEA/CHMP/EWP/192217/2009, 2011.

30. ICH guideline Q2(R1): Validation of Analytical Procedures: Text and Methodology 541 (2005).

31. Chaves, L. L., Lima, S. A. C., Vieira, A. C. C., Barreiros, L., Segundo, M. A., Ferreira, D., Sarmento, B., Reis, S., Nanosystems as modulators of intestinal dapsone and clofazimine delivery. Biomed. Pharmacother. 2018, 103, 1392-1396.

32. Mitri, K., Shegokar, R., Gohla, S., Anselmi, C., Muller, R. H., Lipid nanocarriers for dermal delivery of lutein: Preparation, characterization, stability and performance. Int. J. Pharm. 2011, 414, 267275. 